\title{
High-Energy Impact Behaviors of Hybrid Composite Plates Strengthened with 3D-UHMWPE Composites
}

\author{
Sang-Youl Lee $\mathbb{D}^{1},{ }^{1}$ Gyu-Dong Kim, ${ }^{1}$ Sung Jig Kim, ${ }^{2}$ and Chun-Ho Chang $\mathbb{D}^{3}$ \\ ${ }^{1}$ Department of Civil Engineering, Andong National University, Andong-Si, Gyeongsangbuk-Do, Republic of Korea \\ ${ }^{2}$ Department of Architecture Engineering, Keimyung University, Dalseo-Gu, Daegu 42601, Republic of Korea \\ ${ }^{3}$ Department of Civil Engineering, Keimyung University, Dalseo-Gu, Daegu 42601, Republic of Korea \\ Correspondence should be addressed to Chun-Ho Chang; changclint@gmail.com
}

Received 23 May 2017; Revised 16 December 2017; Accepted 27 December 2017; Published 23 January 2018

Academic Editor: Luigi Di Sarno

Copyright (C) 2018 Sang-Youl Lee et al. This is an open access article distributed under the Creative Commons Attribution License, which permits unrestricted use, distribution, and reproduction in any medium, provided the original work is properly cited.

\begin{abstract}
This study deals with drop-impact effects of new hybrid concrete plates strengthened with an ultrahigh molecular weight polyethylene (UHMWPE). The proposed 3D-UHMWPE results in excellent mechanical properties such as high abrasion resistance, impact strength, and low coefficient of friction. These special properties allow the product to be used in several high-performance applications. In this study, we used two kinds of high-performance materials for the impact reinforcement of a structure made of conventional materials such as a concrete. In particular, the impact mechanism of a fiber-concrete hybrid structure was studied using various parameters. The parametric studies are focused on the various effects of drop-impact on the structural performance. The combined effects of using different fiber-reinforced materials on the impact behavers are also investigated.
\end{abstract}

\section{Introduction}

Impact resistance is one of the most important properties for component designers to consider as well as the most difficult to quantify. It is a critical measure of service life, and more importantly these days it measures the safety and reliability of the structure. In particular, civil structures show various impact effects caused by earthquakes, car crashes, unpredictable blasting loading, and so on. Concretes are mostly used as construction materials; however, they are vulnerable to impact loads because of their brittleness. Fiberreinforced polymers (FRPs) have been commonly used in the field of civil engineering to reinforce concrete in the last few decades [1-4]. This material can be utilized to improve the blast and impact resistance of structures. It has been used for strengthening and retrofitting existing structures, as well as for building new structures including beams, slabs, columns, and walls [5-7]. The use of FRPs has been shown to increase the strength, stiffness, and ductility of structures. Its use has now become popular worldwide because of its superior properties, such as high strength-to-weight ratios and excellent corrosion resistance [8].
Numerical and experimental analyses of structures strengthened with FRPs under static loads have been studied previously using a variety of approaches [9-11]. However, studies concerning the dynamic response of structures strengthened with FRPs are relatively limited. Most studies have investigated the dynamic resistance of these structures against blasting loading, rather than impact loading [12]. Studies of FRP strengthened structures against impact loading are limited by few investigators $[13,14]$. It is necessary to investigate the impact resistance of these structures in order to obtain a better understanding of their response under all loading conditions.

Recently, ultrahigh molecular weight polyethylene (UHMWPE) composites have become increasingly popular for use in various engineering structures. The UHMWPE results in excellent mechanical properties such as high abrasion resistance, high impact strength, and low coefficients of friction. These special properties allow the product to be used in several high-performance applications. For example, Lässig et al. [15] studied the shock response of UHMWPE composites using the inverse planar plate impact test and the shock reverberation technique. Zhang et al. 


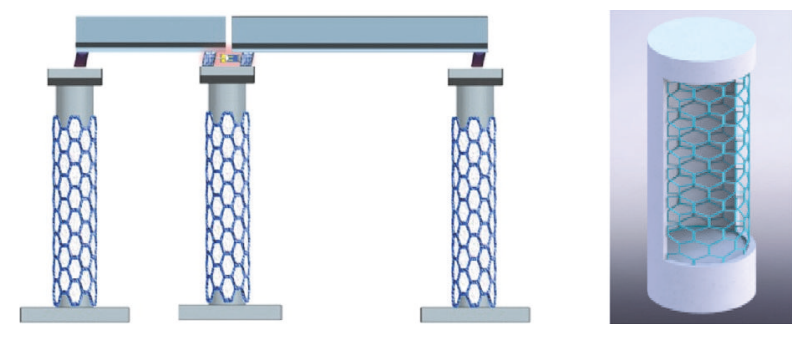

FIGURE 1: Concept applications of concrete columns strengthened with UHMWPE.

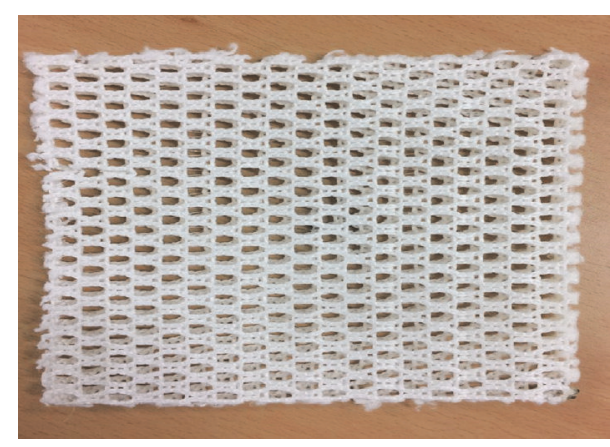

(a) Type A (UHMWPE)

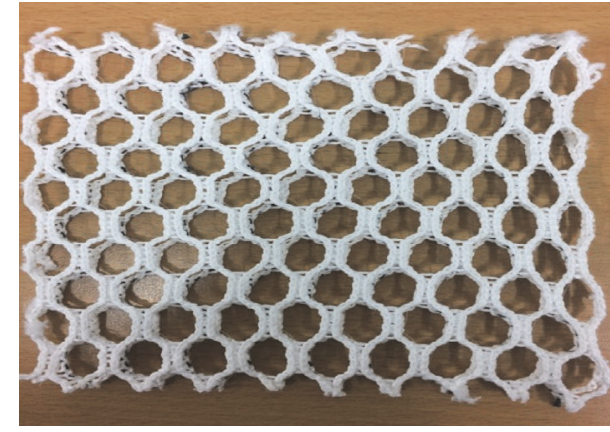

(b) Type B (UHMWPE + carbon fibers)

FIgURE 2: Two kinds of woven UHMWPE specimens.

[16] analyzed the ballistic impact response of UHMWPE composites used in combat helmets. O'Masta et al. [17] studied the ballistic impact response of a UHMWPE fiberreinforced laminate casing of an aluminum alumina hybrid panel. However, these studies do not provide the detailed impact behavior of a concrete reinforced with UHMWPE. There are very few studies that have researched concrete structures strengthened with UHMWPE, and they did not focus on impact loading.

The scope of the aforementioned studies is limited because they analyze only UHMWPE or concretes strengthened with FRPs. Moreover, they mostly focused on blast loading. In this study, we extend previous studies on fiberreinforced concrete to investigate the behavior of concrete strengthened with UHMWPE, subjected to high-energy impact loading due to a heavy weight drop. We use three kinds of experimental models: (1) pure concrete without reinforcement, (2) concrete strengthened with only UHMWPE fabric weaved into fine meshes, and (3) concrete strengthened with a UHMWPE fabric weaved into wide meshes, connected by carbon fibers at the upper and lower face. The displacement, absorption energy, and force due to impact could play a dominant role in determining and efficiently controlling the impact characteristics of concrete structures strengthened with UHMWPE. We also further extend the study to consider the effects of UHMWPE reinforcement using high-resolution thermographic measurement.

\section{Concrete Strengthened with UHMWPE}

UHMWPE has a molecular weight about 10 times higher than that of high density polyethylene (HDPE) resins. These special properties allow the product to be used in several high-performance applications. UHMWPE is sold in powder form in grades that vary according to the molecular weight and average particle size. The molecular weight may be in the low ( 3 million $\mathrm{g} / \mathrm{mol}$ ), medium (5 million $\mathrm{g} / \mathrm{mol}$ ), or high ranges ( 7 to 10 million $\mathrm{g} / \mathrm{mol}$ ). Products with different molecular weights are available in small (average diameter: $\sim 130 \mu \mathrm{m}$ ) or large particle sizes (average diameter: $\sim 190 \mu \mathrm{m}$ ). Figure 1 shows conceptual applications of concrete columns strengthened with a UHMWPE fabric. The hybrid concrete structures strengthened with UHMWPE can reduce the serious effects of impacts such as seismic or blast loading.

Figure 2 shows different types of woven 3D-UHMWPE specimens. In the figure, Type $\mathrm{A}$ is woven using a fine mesh of UHMWPE (Figure 2(a)) in the upper and lower faces, and Type B (Figure 2(b)) is a loose shape tied up using carbon fiber in the upper and lower layers of the UHMWPE. Table 1 shows the material and mechanical properties of UHMWPE and carbon fibers. Figure 3 shows concrete specimens strengthened with Types A and B, which are stacked in a sandwich-like manner. The interface between the concrete and stiffener is bonded using epoxy, as shown in Figure 2(b). Figure 4 shows the manufacturing procedure for UHMWPE-reinforced concrete specimens.

\section{Experimental Setup}

The impact tests were carried out using a drop tower machine (INSTRON CEAST 9350), with a hemispherical impactor with a mass of $1.161 \mathrm{~kg}$ and diameter of $12.7 \mathrm{~mm}$, as shown in Figure 5 [18]. Additional weight was installed for the highenergy impact, and thus a total mass of $35.5 \mathrm{~kg}$ was applied 


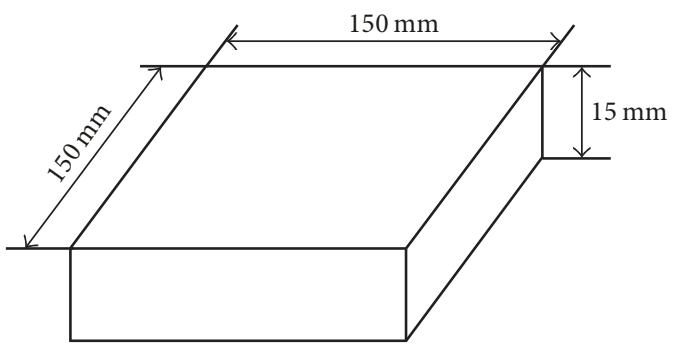

(a) Single concrete

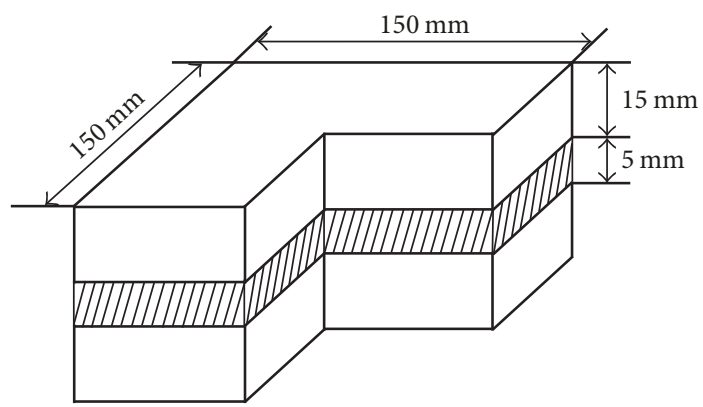

(b) Hybrid concrete

FIgURE 3: Details of single and hybrid concrete specimens.

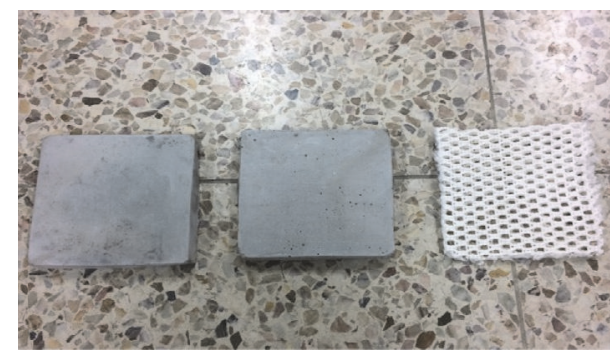

(a)

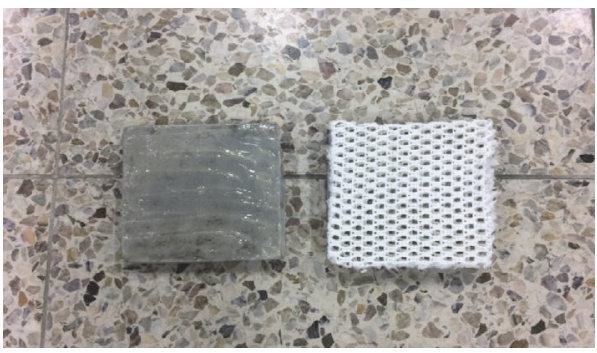

(c)

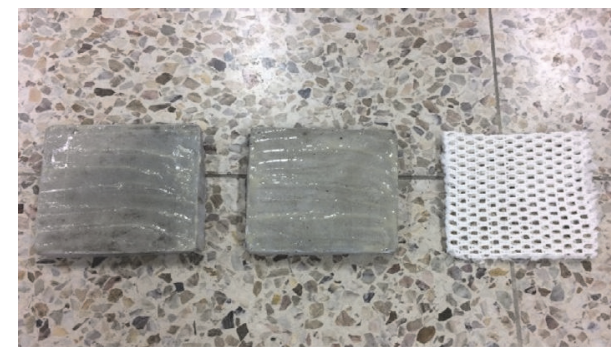

(b)

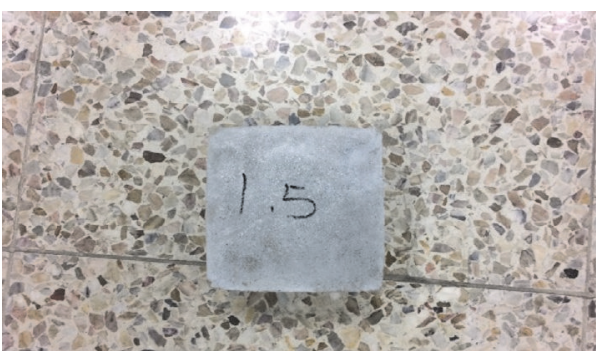

(d)

FIGURE 4: Manufacturing process of UHMWPE reinforced concrete specimens.

TABLE 1: Material and mechanical properties of UHMWPE and carbon fiber.

\begin{tabular}{lcc}
\hline & UHMWPE & Carbon fiber \\
\hline Type code & 1600D/440F & T300 \\
Weight/unit length (Denier) & 1,600 & - \\
Weight/unit length (Decitex) & 1,760 & - \\
Density (g/cm ${ }^{3}$ ) & 0.97 & 1.76 \\
Filaments/tow & 440 & 6,000 \\
Tenacity (g/den) & 32 & - \\
Tenacity (N/tex) & 2.8 & - \\
Tensile strength Gpa & 2.7 & 3,530 \\
Specific modulus (g/den) & 1,100 & - \\
Specific modulus (N/tex) & 97 & - \\
Modulus (Gpa) & 95 & - \\
Elongation at break (\%) & 3.2 & 1.5 \\
Single filament weight (dpf) & 3.6 & - \\
\hline
\end{tabular}

for the experiment. The target material is fixed between upper and lower hollow objects as shown in Figure 5(b). The impact tests were conducted with and without UHMWPE stiffeners using different types of stiffeners and at varying loading magnitudes. Table 2 shows the parameters for the experiments. The magnitude of the applied impact load was appropriately determined to ensure penetration through the specimen by conducting a preliminary test. Displacements, energies, and forces were obtained for each time step by using sensors installed at the tube head.

Figure 6 shows the experimental setup for using the thermographic camera, which can detect invisible damage within structures after impact loading. The other advantage of thermographic measurement is that it does not require contact sensors like ultrasonic measurements do. The nondestructive evaluation was carried out using an FLIR A600Series IR camera with $640 \times 480$ pixels and temperature ranges of $-20-350^{\circ} \mathrm{C}\left(\mathrm{NETD}: 0.05^{\circ} \mathrm{C}\right)$ using a $2 \mathrm{KW}$ Halogen lamp for heating. 


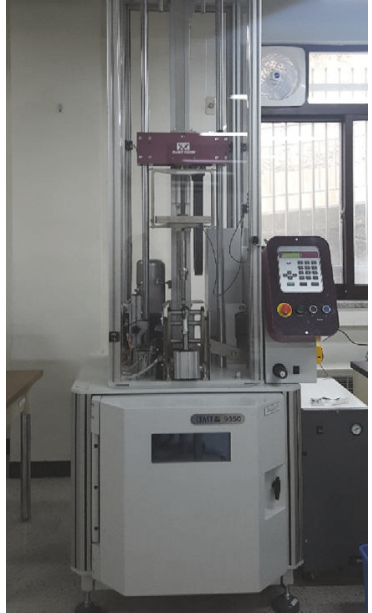

(a) Impact tower

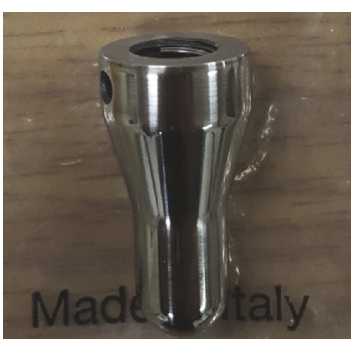

(c) Tup head

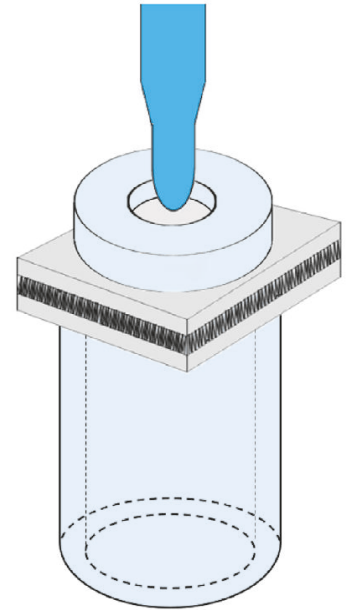

(b) Specimen installation

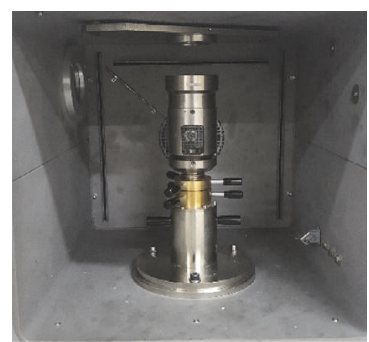

(d) Sensor part

FIgURE 5: Drop-induced impact test instruments.

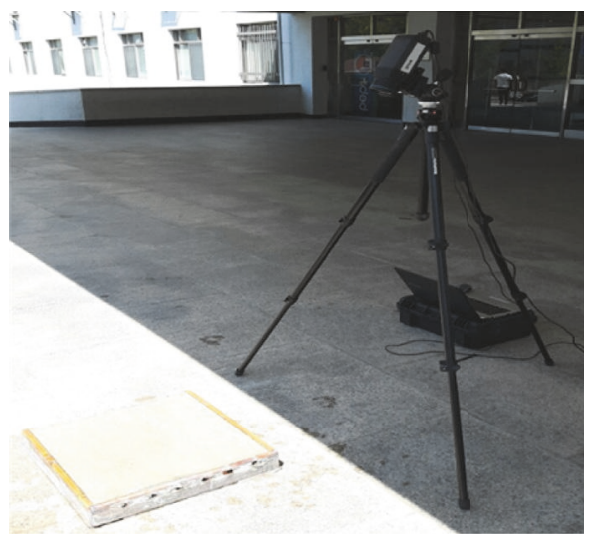

(a)

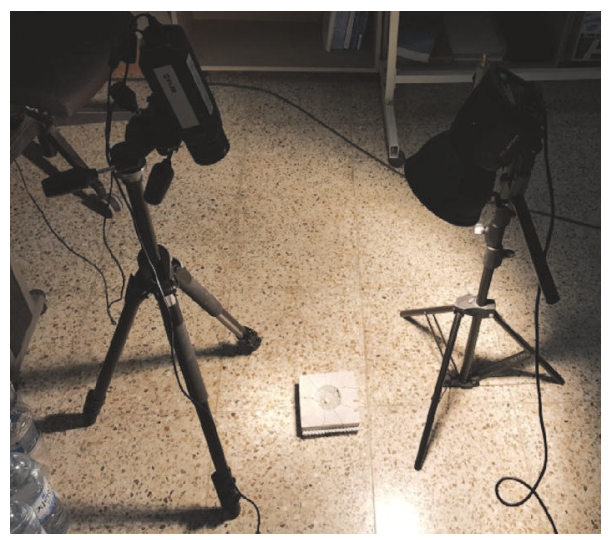

(b)

FIGURE 6: Thermographic measurement.

\section{Results and Discussions}

4.1. Fracture Shapes. Figure 7 shows a comparison of the high-energy impact-induced fracture shapes for Cases I, II, and III. The drop-impact load of $260 \mathrm{~J}(35.5 \mathrm{~kg})$ at a velocity of $3.63 \mathrm{~m} / \mathrm{s}$ is applied for all the cases. It can be observed from the figure that the specimen in Case I is completely broken and separated by the impact load, because it is a pure concrete specimen without UHMWPE reinforcement. For Cases II and III, the specimens are damaged but maintain their shape due to the reinforcements. The specimen in Case II shows better resistance against impact loading compared to that in Case III. In addition, the specimen in Case II is not completely penetrated by the impact, but that in Case III is completely penetrated on both sides. However, the concrete plate in Case III is not fragmented even though it is cracked and penetrated around the area of impact loading. This phenomenon is similar in the case of an impact loading of $270 \mathrm{~J}$ with a velocity of $3.73 \mathrm{~m} / \mathrm{s}$, as shown in Figure 8 . In the figure, the penetrated hole size in Case VI is larger than that in 


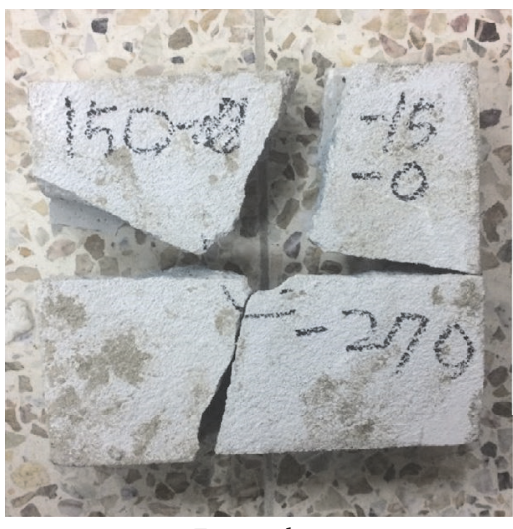

Front side

(a) Case I

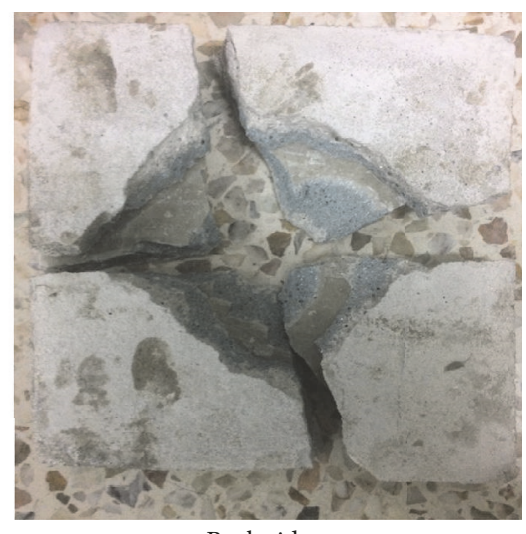

Back side

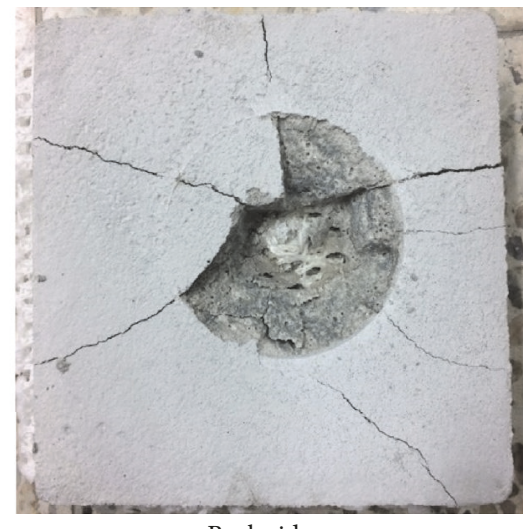

Back side

(b) Case II

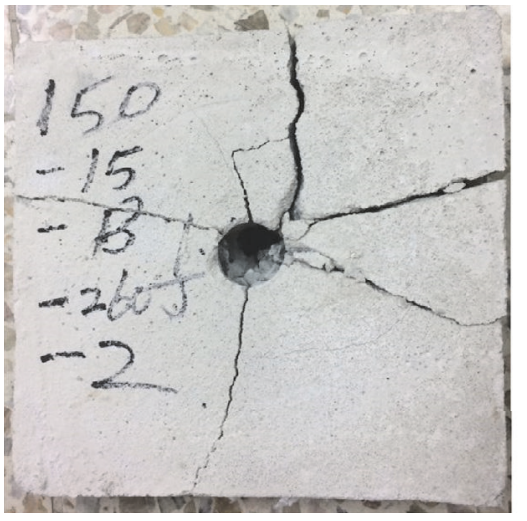

Front side

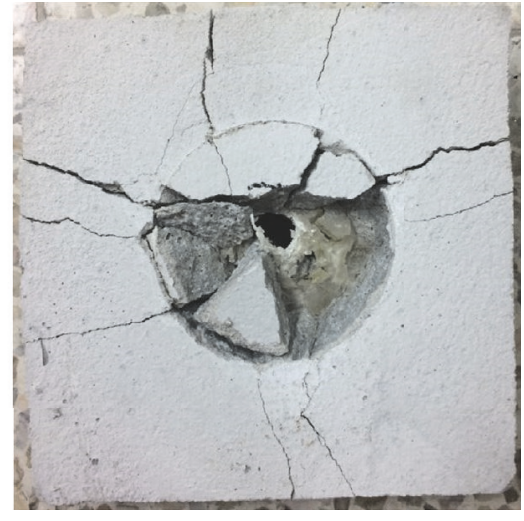

Back side

(c) Case III

FIGURE 7: Comparison of impact induced fracture shapes for different cases (impact load: $260 \mathrm{~J}$ ).

Case III because of the increased impact load. However, Cases III and VI also show good performances in preventing the fragmentation of concrete. Among the experimental cases, Cases II and V using UHMWPE with fine meshes show the best impact-absorbing capacity.

Therefore, it can be concluded that the reinforcement using a simple UHMWPE mesh without carbon fiber is sufficient to protect concrete structures from impact effects. However, Figures 7 and 8 suggest that the influence of carbon fibers in UHMWPE with wide meshes (Cases III and VI) may also play a role in reducing the serious damage due to an impact.

4.2. Displacements. Figure 9 shows a comparison of the induced displacements with increasing time steps. The central displacements are measured for different impact loads for six cases. It can be observed from the figure that the induced displacements for Cases I and IV tend to increase 


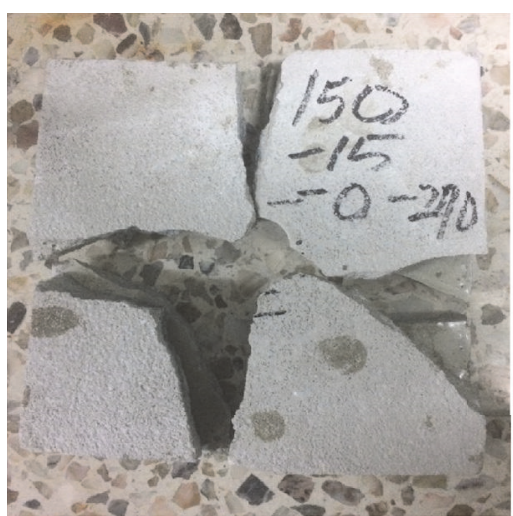

Front side

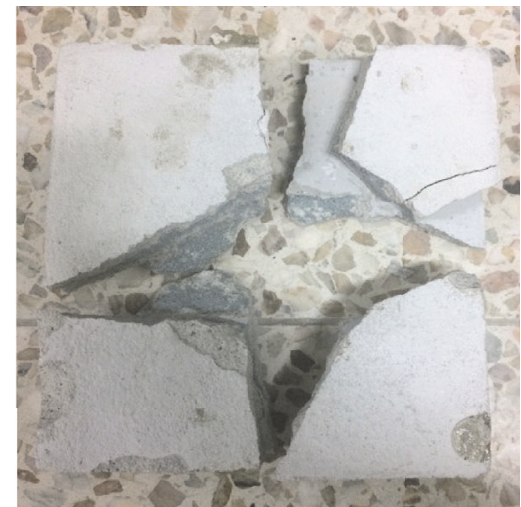

Back side

(a) Case IV

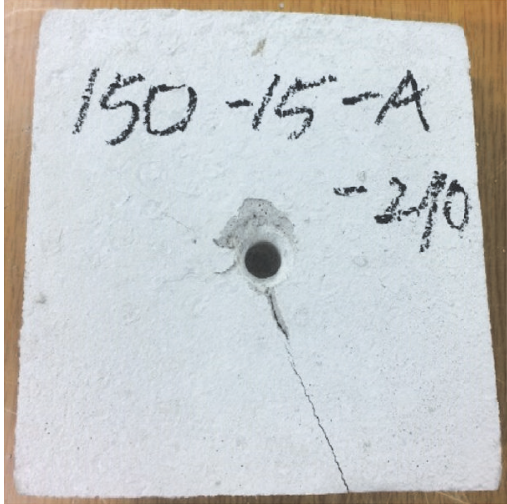

Front side

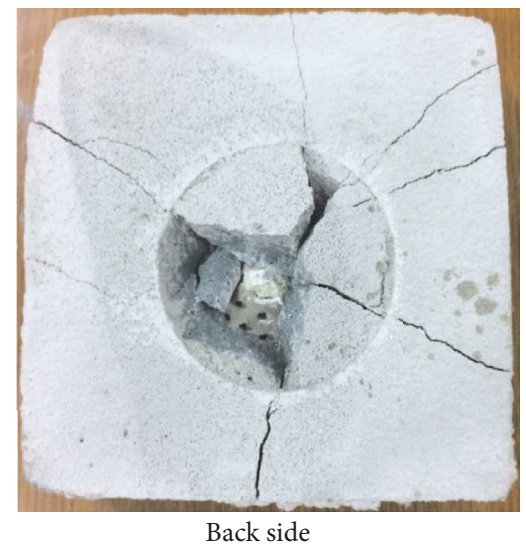

(b) Case V

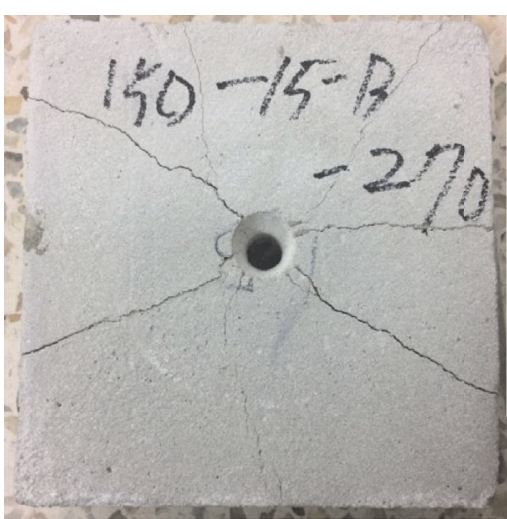

Front side

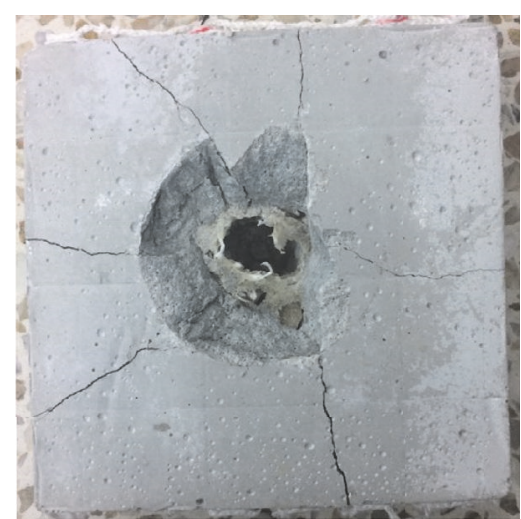

Back side

(c) Case VI

FIGURE 8: Comparison of impact induced fracture shapes for different cases (impact load: $270 \mathrm{~J}$ ).

sharply in the same range. This is because the pure concrete under impact loading shows a brittle fracture trend. However, the displacement of concrete plates with UHMWPE approaches a constant value with time increases. This is because the displacement may be significantly influenced by UHMWPE. The displacements in Cases II and V (Type A) are $20-25 \%$ lower than those in Cases III and VI (Type B) because of the aforementioned reason. For the impact load of $260 \mathrm{~J}$, the displacement in Case II is $15-20 \%$ lower than that in Case III. We can observe from the figure that the differences in displacements increase for higher energy impact load. Displacements for impact load of $270 \mathrm{~J}$ are different by $25-35 \%$. From the results, it may be concluded from the results that the resistance in Cases II and V to impact loading is superior to that in the others.

4.3. Impact Absorption Energies and Forces. The main purpose of an impact test is to determine the absorption energy 


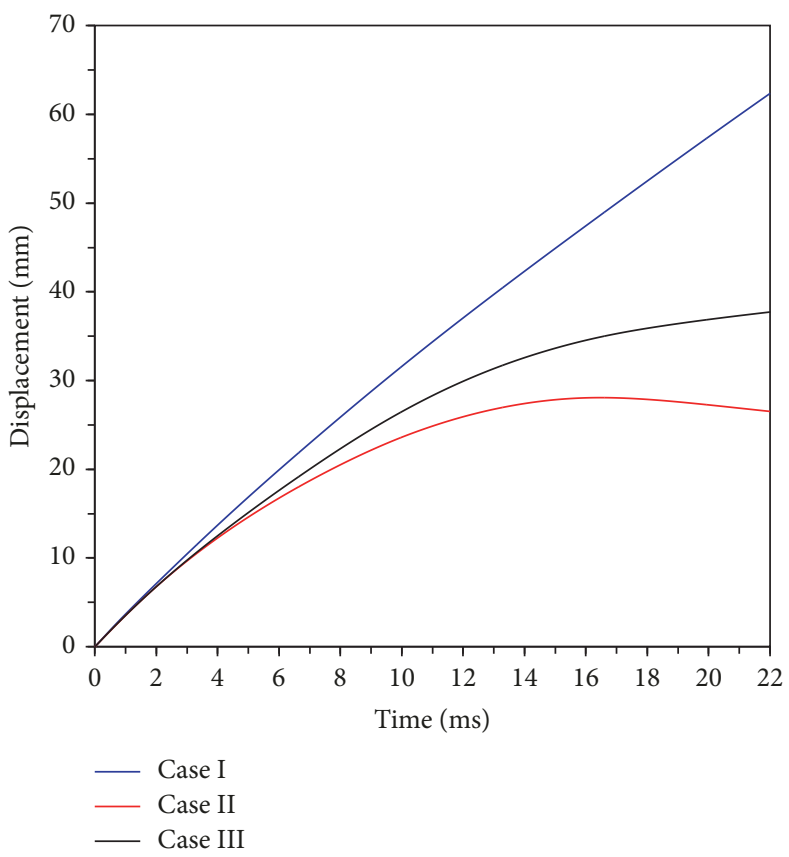

(a) Impact load $=260 \mathrm{~J}$

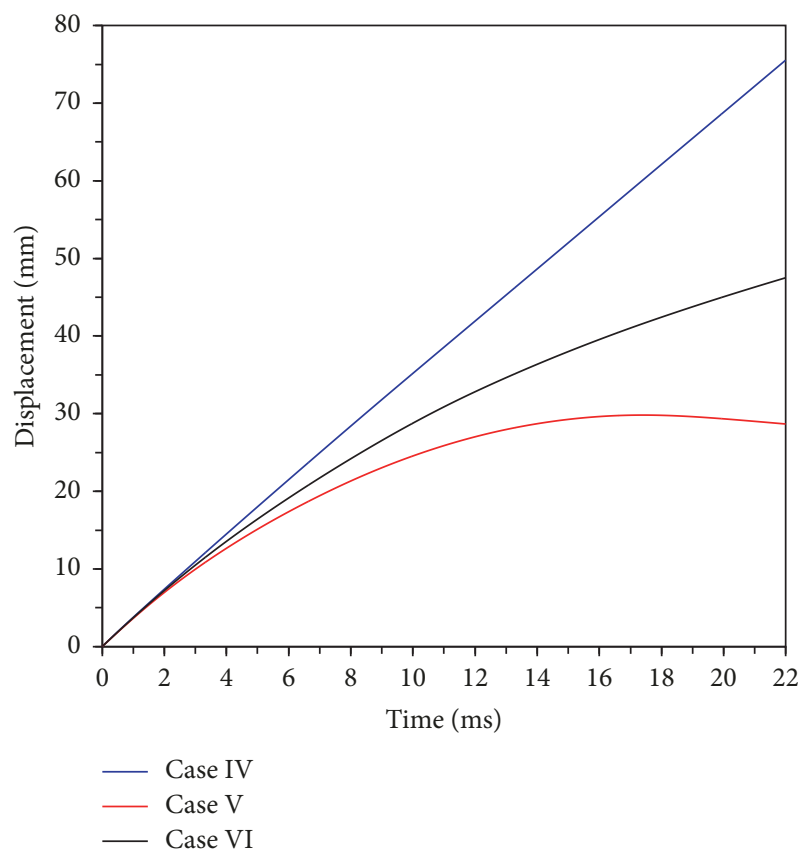

(b) Impact load $=270 \mathrm{~J}$

FIGURE 9: Comparison of impact induced displacements for different cases.

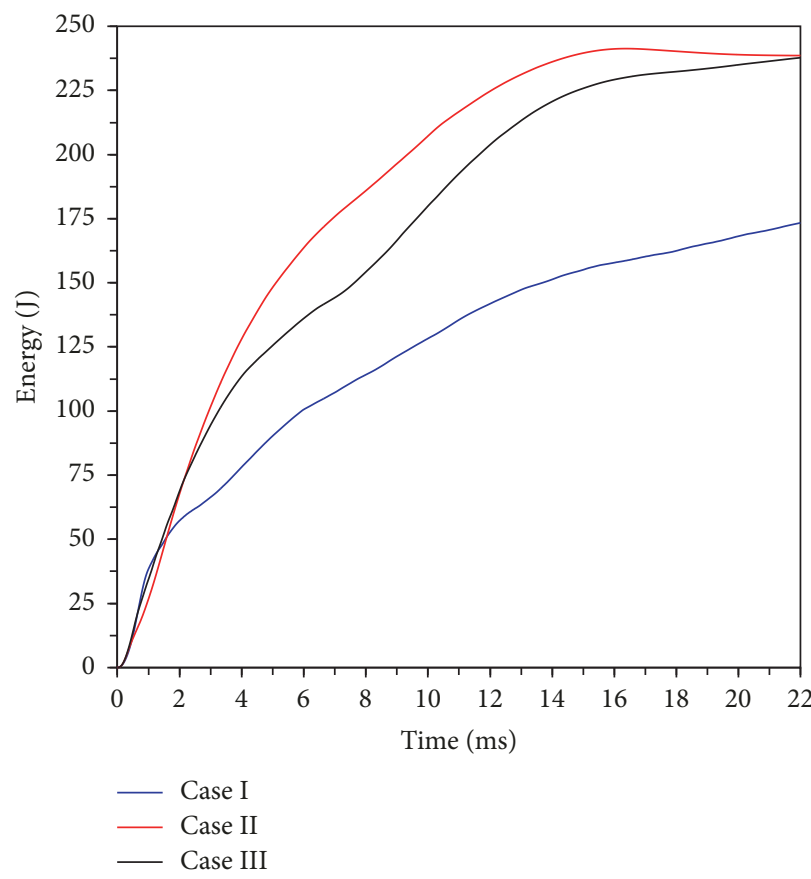

(a) Impact load $=260 \mathrm{~J}$

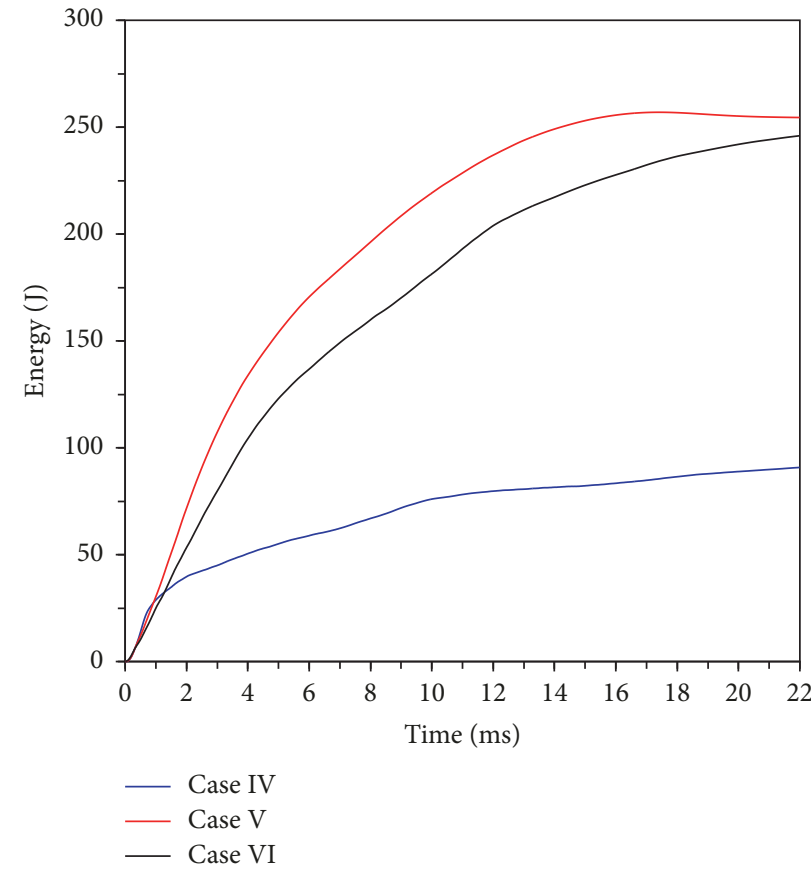

(b) Impact load $=270 \mathrm{~J}$

Figure 10: Comparison of impact absorption energies for different cases.

required for a specimen to be fractured by impact loading. Figure 10 shows comparisons of the impact absorption energies for different cases. For all the cases, the curves tend to increase with time and approach a constant at the maximum point. This means that the impact energy is completely used for the fracture of specimens and there are not any energy transformations to the tup head due to the elastic behavior. For Cases I and IV, the induced absorptive energies for $260 \mathrm{~J}$ are $25-35 \%$ lower than those for others. The difference becomes more dramatic (over 50\%) for the case of the $270 \mathrm{~J}$ shown in Figure 10(b). We can also observe from the figure that the impact absorption energies for Type A are 10-15\% 


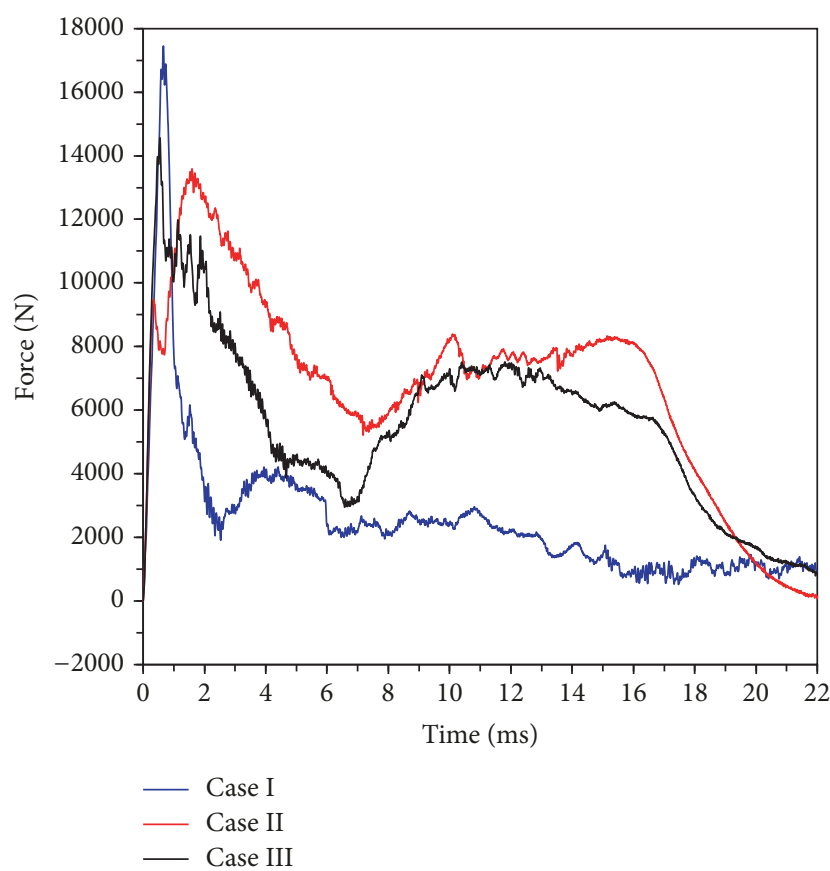

(a) Impact load $=260 \mathrm{~J}$

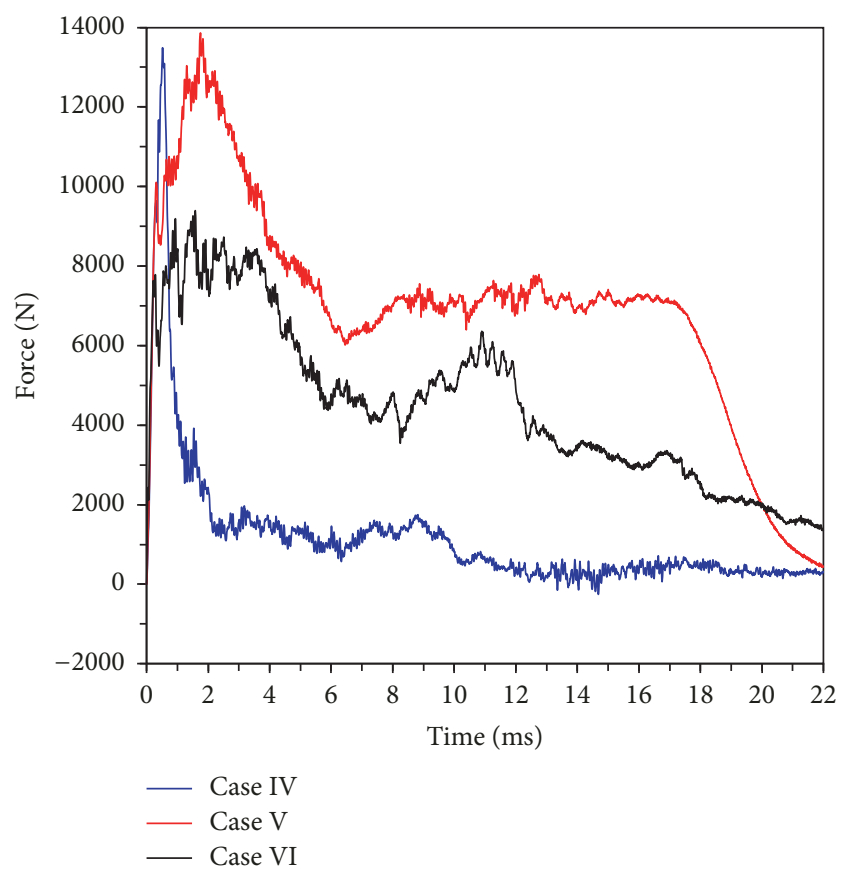

(b) Impact load $=270 \mathrm{~J}$

FIGURE 11: Comparison of impact absorptions for different cases.

TABLE 2: Case parameters of experiments.

\begin{tabular}{lcc}
\hline Case & Impact load $(\mathrm{J})$ & Stiffener \\
\hline I & & - \\
II & 260 & Type A \\
III & & Type B \\
\hline IV & \multirow{2}{*}{270} & - \\
V & & Type A \\
VI & & Type B \\
\hline
\end{tabular}

higher than those for Type B for both impact loads. For the concrete plates with UHMWPE, it is observed that the difference in impact energies is negligible with increasing time. This observation shows that it could be possible to use UHMWPE with wider meshes to design a hybrid concrete structure, especially when carbon fibers connect the lower and upper faces.

Figure 11 shows a comparison of the impact absorption forces for different cases. We can see that the forces in Cases II and III for the load of $260 \mathrm{~J}$ increase by $30-50 \%$ in the 6-16 ms range when compared with Case I. Cases for the load of $270 \mathrm{~J}$ show similar trends. This is because concretes reinforced with UHMWPE are prone to ductile fracture caused by the absorption of impact. In contrast, impact absorption forces for concretes without UHMWPE decrease with time because of the brittle fracture.

4.4. Thermographic Evaluation. We carried out thermographic evaluations of specimens damaged after the impact loading. Figures 12-15 show comparisons of thermographic measurements for different cases. The specimens were heated by a sunlight or a Halogen lamp as shown in Figure 6, and then the heating sources were removed to cool off the specimens. The internal damage regions are identified by detecting different reactions in temperature during cooling off. The red colors in the figures indicate higher temperature reactions in representing damaged regions.

Figure 12 shows a comparison of thermographic measurements at the front side for impact loading of $260 \mathrm{~J}(3.63 \mathrm{~m} / \mathrm{s})$ for Cases II and III. We can see cracks around the hole and their propagations. This observation can be seen more clearly on the back side, as shown in Figure 13. Figures 14 and 15 show a comparison of the results for an impact loading of $270 \mathrm{~J}$. Internal cracks around the hole are observed owing to differences in the temperature reaction under cooling after heating. The damage regions in Cases II and V are smaller than those in Cases III and VI. However, the difference is not significant for front sides. On the other hand, for the back sides the internal damage regions of Type B (Case VI) are somewhat slightly larger than those of Type A (Case V). However, the 3D-UHMWPE fabric with wider meshes in Case B also has excellent resistance against impact loading, because the mixed carbon fibers play a role in tying up the fabric.

\section{Summary and Conclusions}

In this study, an experimental approach for identifying damage and resistances in new 3D- UHMWPE reinforced concretes under impact loads is proposed. To compare effects of the UHMWPE composites against impacts, three kinds of experimental models were schemed and tested for six 

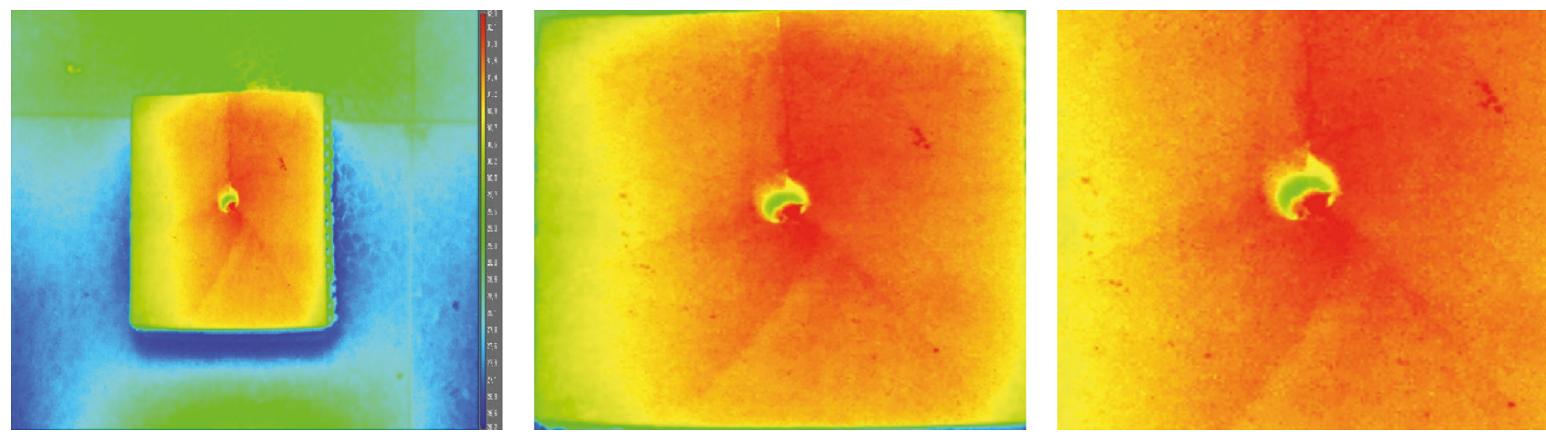

(a) Case II
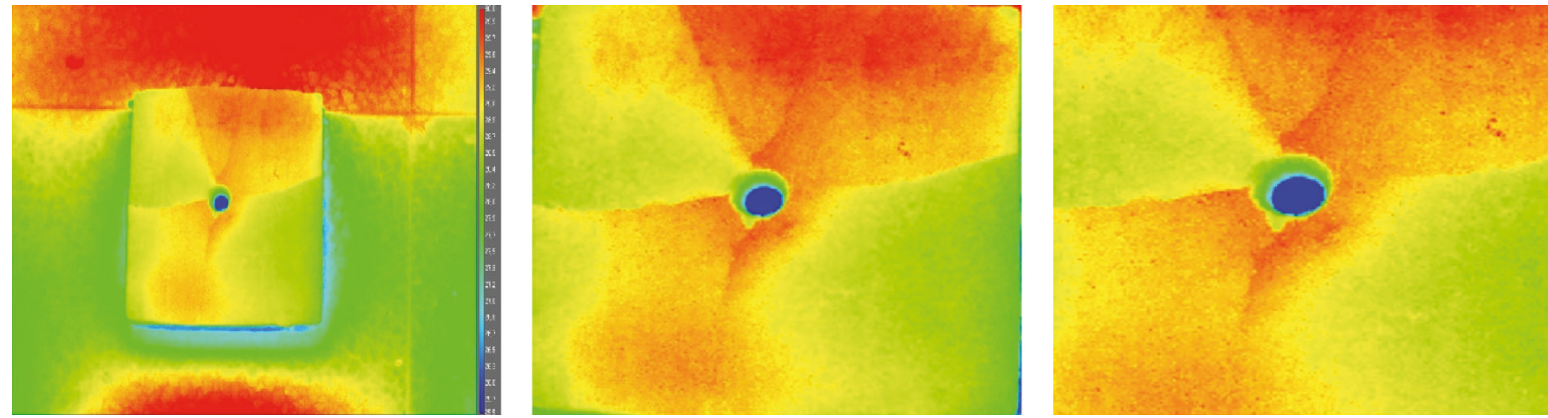

(b) Case III

FIGURE 12: Comparison of thermographic measurements for impact loading of $260 \mathrm{~J}$ (front side).
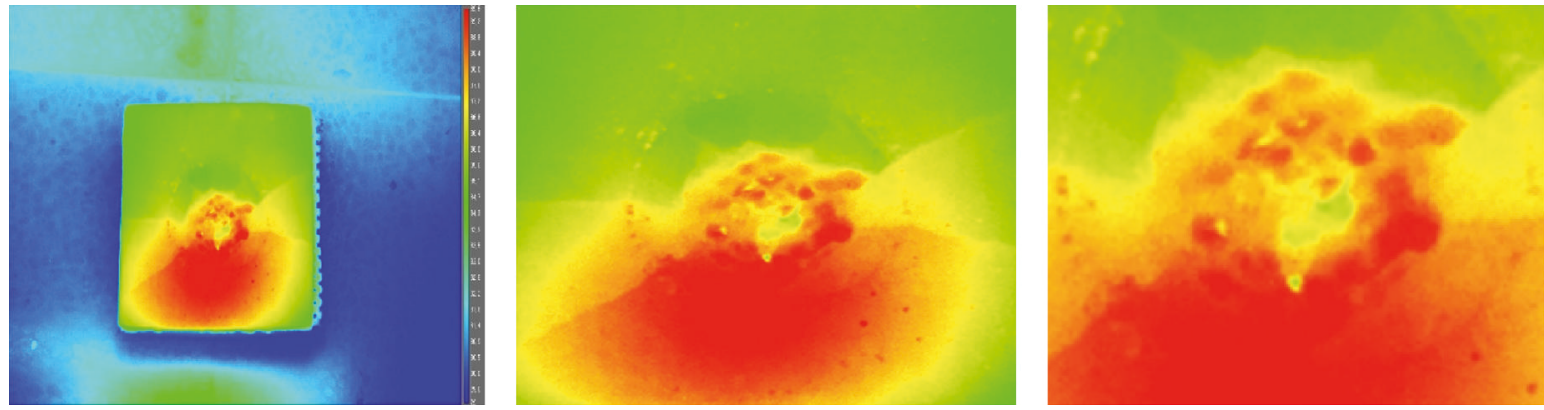

(a) Case II
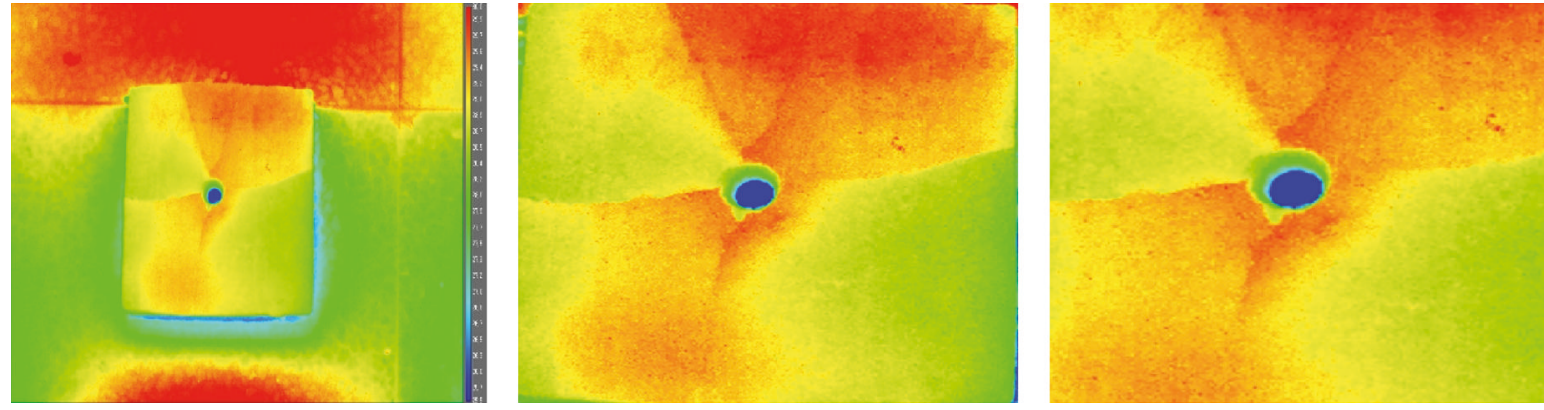

(b) Case III

FIGURE 13: Comparison of thermographic measurements for impact loading of $260 \mathrm{~J}$ (back side). 


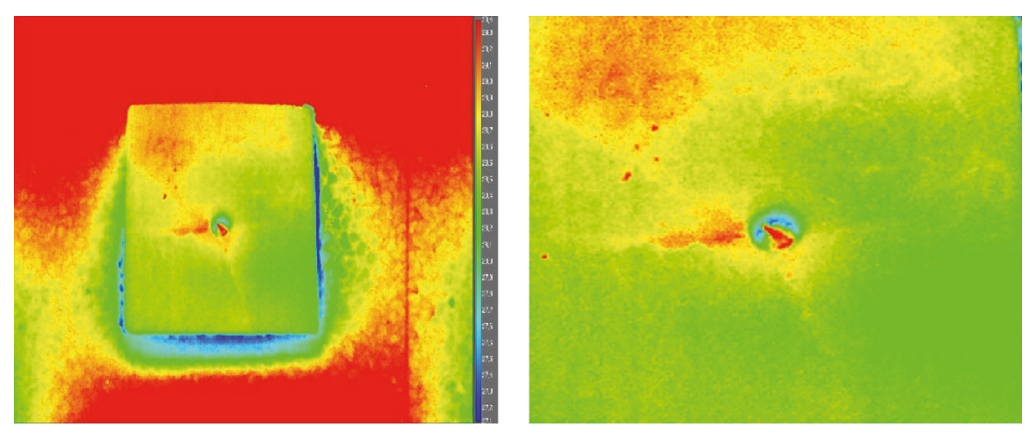

(a) Case V
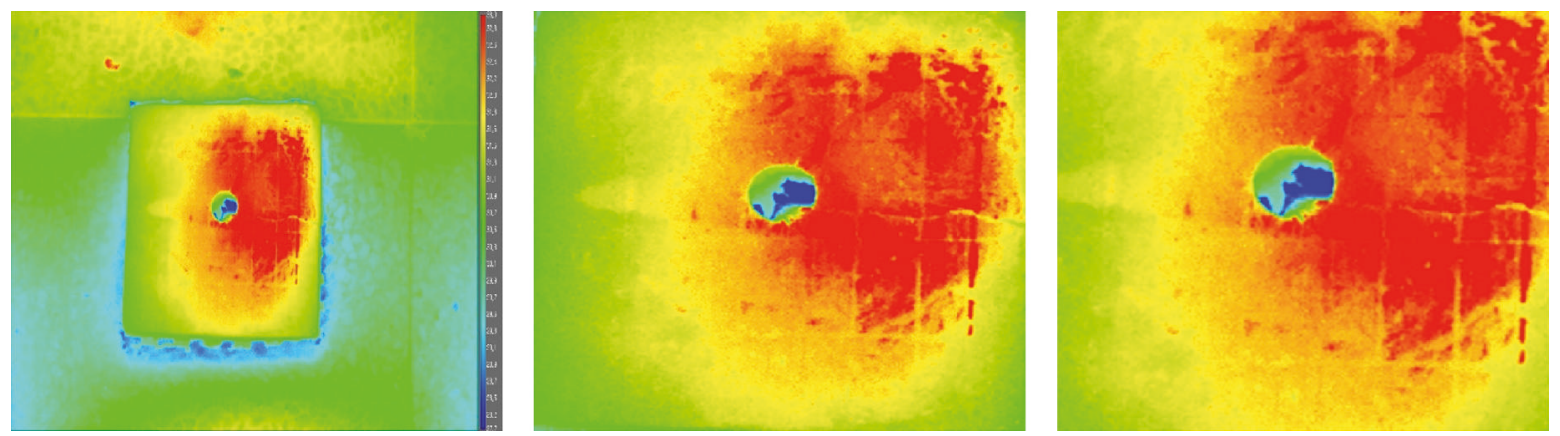

(b) Case VI

FIGURE 14: Comparison of thermographic measurements for impact loading of $270 \mathrm{~J}$ (front side).
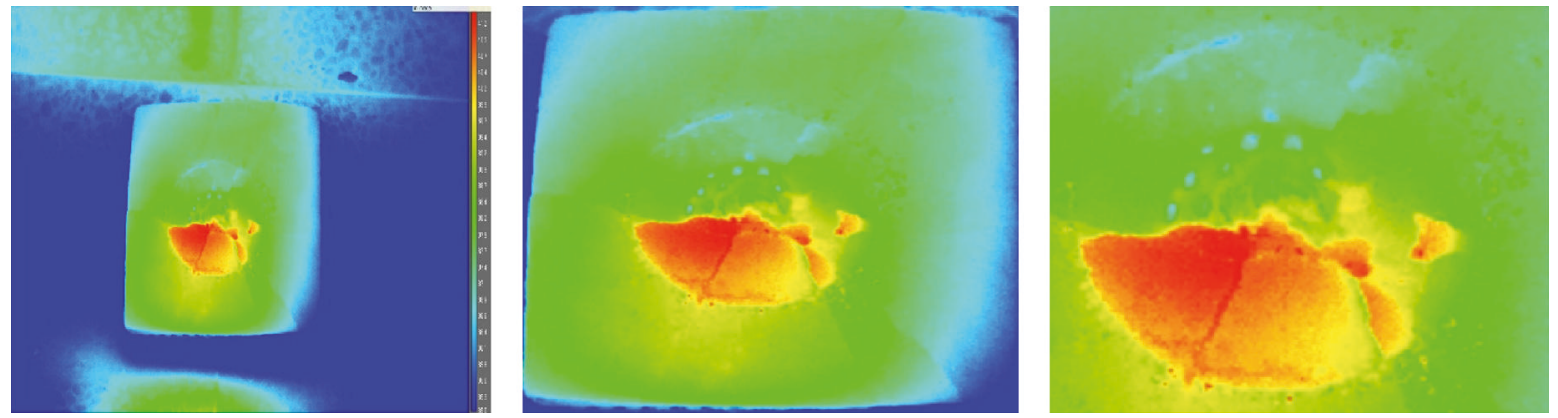

(a) Case V
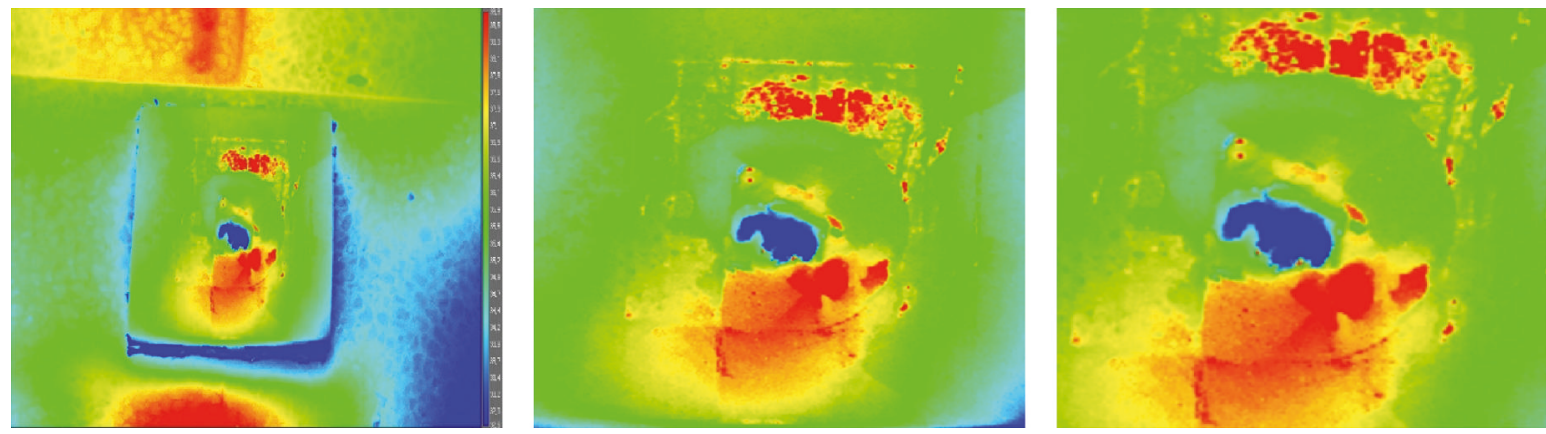

(b) Case VI

FIGURE 15: Comparison of thermographic measurements for impact loading of $270 \mathrm{~J}$ (back side). 
parameter cases. For nondestructive evaluation, the specimens after impact loading are inspected in the thermographic measuring procedure. Based on the numerical results, the following conclusions are derived.

(1) It is recommended to use the proposed 3DUHMWPE fabric not only to reduce significantly the brittle fracture of conventional concretes but also to control the resistance depending on optimal designs for the hybrid structure.

(2) The reinforcement using a simple UHMWPE without carbon fiber is sufficient to protect concrete structures from impact effects. However, the influence of carbon fibers in UHMWPE with wide meshes may also play certain roles in reducing the serious damage due to impact.

(3) The nondestructive evaluation using a thermographic measurement can detect invisible damage within structures after impact loading, especially for noncontact cases. Damage regions in concentrates using UHMWPE with fine meshes are smaller than those in wider meshed UHMWPE tied by Carbon fibers; however the difference is not significant for these cases.

(4) For the 3D-UHMWPE fabric with wider meshes, hybrid composites tied by carbon fibers could be recommendable, because carbon fibers play a significant role in the better resistances against impact loading.

It is concluded from this study that the proposed hybrid concrete structures strengthened with 3D-UHMWPE fabric works well for a drop-induced impact loading. However, it is necessary that this study should be extended to more realistic dynamic load cases. In addition, for more realistic situations, more advanced studies that can identify the condition of hybrid structures strengthened with optimized 3D-UHMWPE fabrics

\section{Conflicts of Interest}

The authors declare that there are no conflicts of interest regarding the publication of this paper.

\section{Acknowledgments}

This work was supported by the National Research Foundation of Korea (NRF) grant funded by the Korea government (MSIP) (no. 2015R1A2A2A01005637).

\section{References}

[1] L. C. Bank, Composites for Construction: Structural Design with FRP Materials, John Wiley \& Sons, Hoboken, NJ, USA, 2006.

[2] D. J. Oehlers and R. Seracino, Design of FRP and Steel Plated RC Structures: Retrofitting Beams and Slabs for Strength, Stiffness and Ductility, Elsevier, Oxford, UK, 2004.

[3] J. G. Teng, J. F. Chen, S. T. Smith, and L. Lam, FRP-Strengthened RC Structures, John Wiley \& Sons, Chichester, UK, 2002.
[4] L. C. Hollaway and J. G. Teng, Strengthening and Rehabilitation of Civil Infrastructures Using Fibre-Reinforced Polymer (FRP) Composites, Elsevier, 2008.

[5] Y.-F. Wu and C. Jiang, "Effect of load eccentricity on the stress-strain relationship of FRP-confined concrete columns," Composite Structures, vol. 98, pp. 228-241, 2013.

[6] A. Nanni and N. M. Bradford, "FRP jacketed concrete under uniaxial compression," Construction and Building Materials, vol. 9, no. 2, pp. 115-124, 1995.

[7] L. Nguyen-Minh and M. Rovňák, "Shear resistance of GFRPreinforced concrete beams," Magazine of Concrete Research, vol. 63, no. 3, pp. 215-233, 2011.

[8] T. M. Pham and H. Hao, "Review of concrete structures strengthened with FRP against impact loading," Structures, vol. 7, pp. 59-70, 2016.

[9] ACI 440.2R-08, Guide for the design and construction of externally bonded FRP Systems for Strengthening Concrete Structures, 4402R-08, American Concrete Institute, Farmington Hills, Mich, USA, 2008.

[10] TR 55, Design Guidance for Strengthening Concrete Structures Using Fibre Composite Materials, Concrete Society, Camberley, UK, 2012.

[11] fib, "Externally bonded FRP reinforcement for RC structures," Tech. Rep. Bulletin no. 14, 2001.

[12] P. A. Buchan and J. F. Chen, "Blast resistance of FRP composites and polymer strengthened concrete and masonry structures-a state-of-the-art review," Composites Part B: Engineering, vol. 38, no. 5-6, pp. 509-522, 2007.

[13] T. M. Pham and H. Hao, "Axial impact resistance of FRPconfined concrete," Journal of Composites for Construction, vol. 21, no. 2, Article ID 04016088, 2017.

[14] R. Wang, L.-H. Han, and Z. Tao, "Behavior of FRP-concretesteel double skin tubular members under lateral impact: Experimental study," Thin-Walled Structures, vol. 95, article no. 4560, pp. 363-373, 2015.

[15] T. Lässig, F. Bagusat, M. May, and S. Hiermaier, "Analysis of the shock response of UHMWPE composites using the inverse planar plate impact test and the shock reverberation technique," International Journal of Impact Engineering, vol. 86, pp. 240 248, 2015.

[16] T. G. Zhang, S. S. Satapathy, L. R. Vargas-Gonzalez, and S. M. Walsh, "Ballistic impact response of Ultra-High-MolecularWeight Polyethylene (UHMWPE)," Composite Structures, vol. 133, pp. 191-201, 2015.

[17] M. R. O’Masta, B. G. Compton, E. A. Gamble, F. W. Zok, V. S. Deshpande, and H. N. G. Wadley, "Ballistic impact response of an UHMWPE fiber reinforced laminate encasing of an aluminum-alumina hybrid panel," International Journal of Impact Engineering, vol. 86, pp. 131-144, 2015.

[18] Z. Sharif-Khodaei, M. Ghajari, and M. H. Aliabadi, "Impact damage detection in composite plates using a self-diagnostic electro-mechanical impedance-based structural health monitoring system," Journal of Multiscale Modelling, vol. 6, no. 4, pp. $1-20,2015$. 


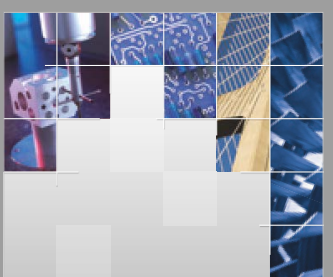

\section{Enfincering}
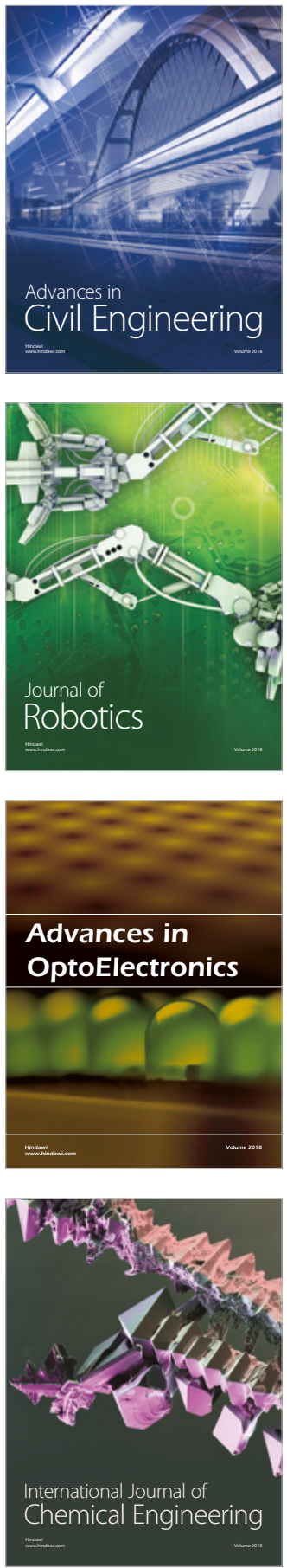

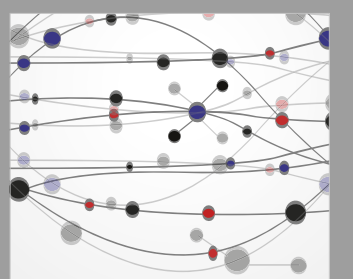

\section{Rotating \\ Machinery}

The Scientific World Journal

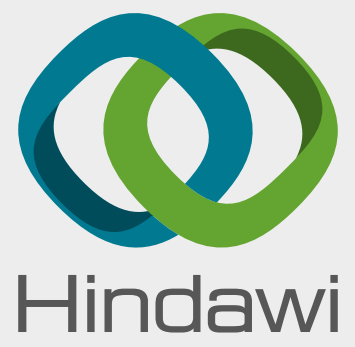

Submit your manuscripts at

www.hindawi.com
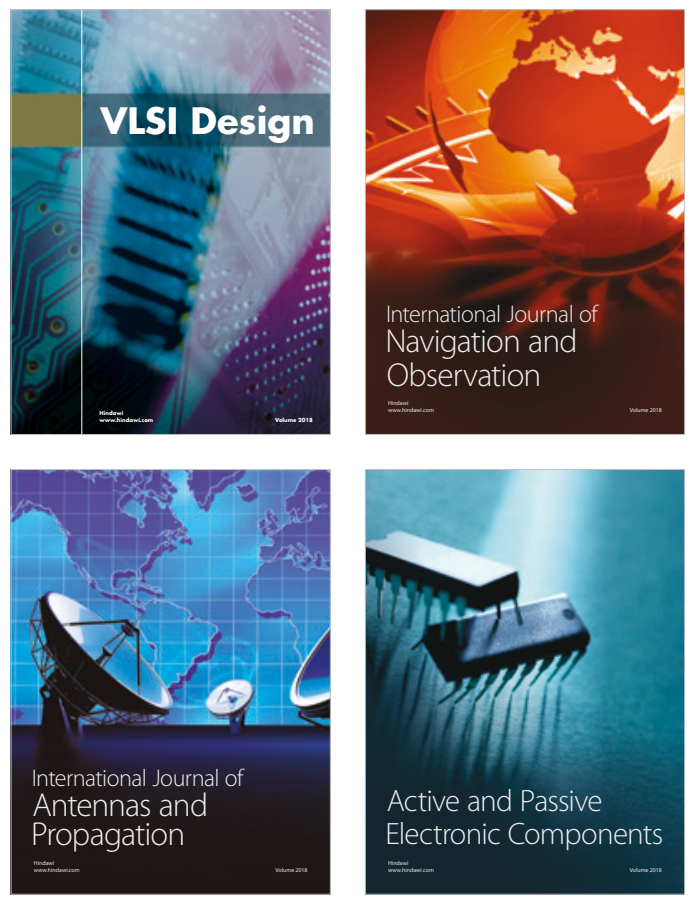
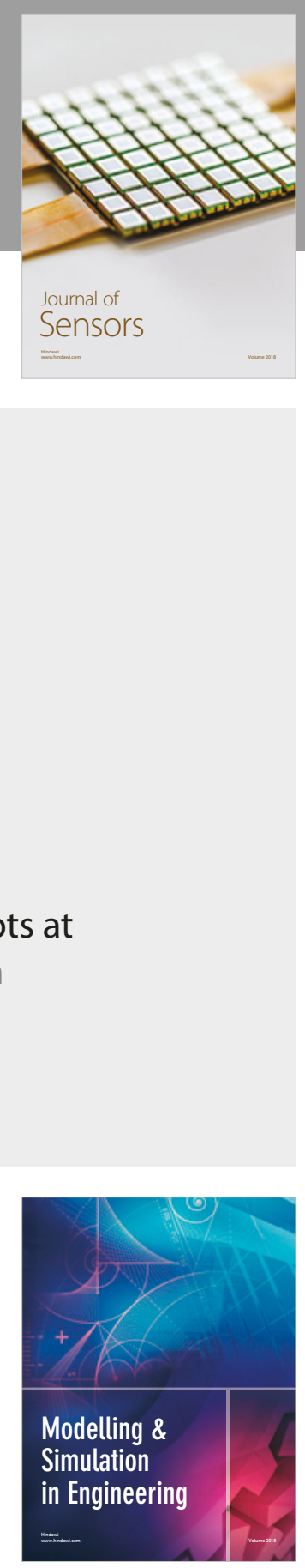

\section{Advances \\ Multimedia}
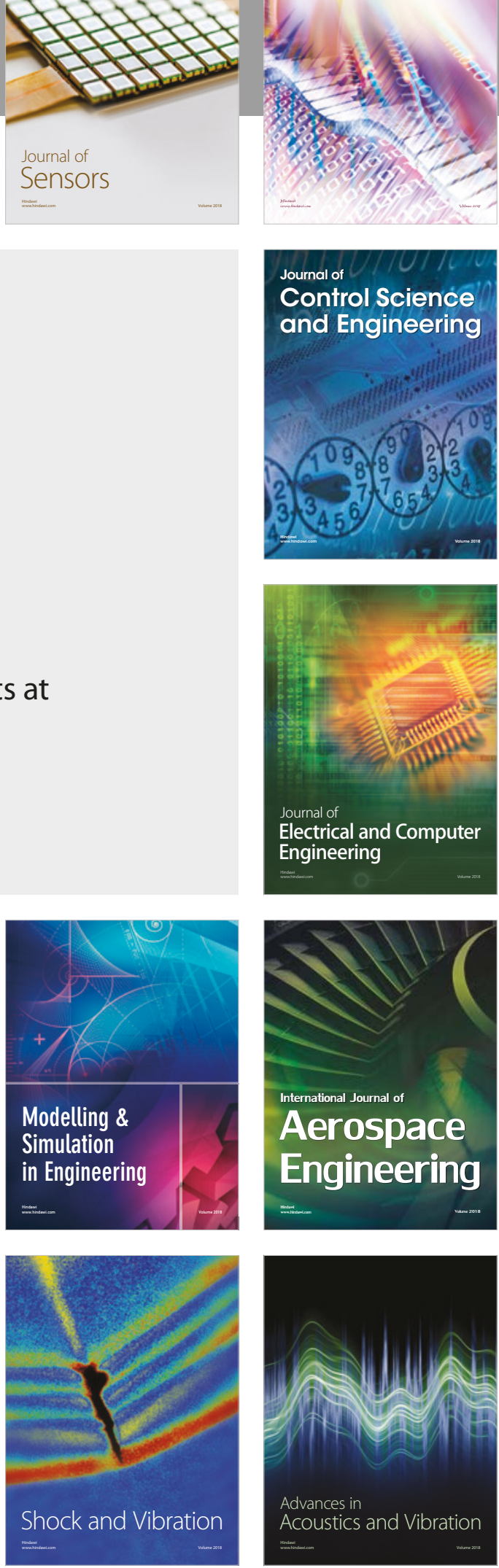